Territorios 39 / Bogotá, 2018, pp. 71-95

ISSN: 0123-8418

ISSNe: 2215-7484

La diversidad de la securización urbana: dimensiones, actores y retos

\title{
La inseguridad en el transporte público del Área Metropolitana de Buenos Aires. Experiencias y percepciones de mujeres \\ y varones
}

Insecurity in Public Transport in the Metropolitan Area of Buenos Aires. Experiences and Perceptions of Women and Men A insegurança no transporte público da Área Metropolitana de Buenos Aires. Experiências e percepções de mulheres e homens

Leda Paula Pereyra*

Andrea Gutiérrez

Mariela Mitsuko Nerome ${ }^{\star \star \star}$

Recibido: 30 de noviembre de 2017

Aprobado: 26 de abril de 2018

Doi: http://dx.doi.org/10.12804/revistas.urosario.edu.co/territorios/a.6310

Para citar este artículo:

Pereyra, L. P., Gutiérrez, A., \& Nerome, M. M. (2018). La inseguridad en el transporte público del Área Metropolitana de Buenos Aires. Experiencias y percepciones de mujeres y varones. Territorios (39), 71-95. Doi: http://dx.doi.org/10.12804/revistas.urosario.edu.co/territorios/a.6310

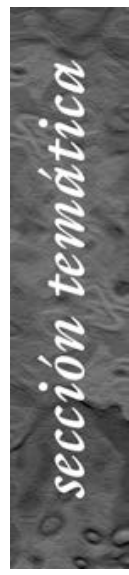

* Universidad de Buenos Aires. Facultad de Filosofia y Letras. Instituto de Geografía "Romualdo Ardissone”. Programa de Transporte y Territorio. Buenos Aires, Argentina. Correo electrónico: ledapereyra@hotmail.com.ORCID: https://orcid.org/00000001-9702-4145

** Universidad de Buenos Aires. Facultad de Filosofía y Letras. Instituto de Geografía "Romualdo Ardissone”. Programa de Transporte y Territorio. Buenos Aires, Argentina. CONICET. Buenos Aires, Argentina. Correo electrónico: angut2@gmail. com. ORCID: https://orcid. org/0000-0002-8124-1679

*** Dirección Nacional de Innovación y Desarrollo Sostenible, Ministerio del Interior, Obras Públicas y Vivienda/FADU, 
Palabras clave

Movilidad cotidiana, inseguridad, transporte público, género, estrategias.

Keywords

Daily mobility, insecurity, public transport, gender, strategies.

Palavras-chave

Mobilidade cotidiana, insegurança, transporte público, gênero, estratégias.

\section{territarias 39}

\section{RESUMEN}

El trabajo busca visibilizar una forma de la inseguridad ciudadana aun no analizada en profundidad: aquella en el transporte público. Si bien, la vulneración de la seguridad es un condicionante socioeconómico y espacial que limita el acceso a los bienes, servicios, actividades y oportunidades ofrecidas por las ciudades, tanto a mujeres como a varones, su percepción y experiencia son dos dimensiones de la inseguridad que tienen un efecto diferente sobre las mujeres. A partir de una exploración sobre las diferencias en la percepción de inseguridad y en la efectiva victimización de usuarias y usuarios del transporte público en el Área Metropolitana de Buenos Aires (AMBA), se indaga en las estrategias de movilidad cotidiana de las mujeres vinculadas con la inseguridad como problema en el transporte público. Se presenta evidencia - basada en información primaria cualicuantitativa y relevada en el marco del estudio comparativo latinoamericano "Ella se mueve segura"- sobre el desempeño de la inseguridad como condicionante de género, y sobre una forma de violencia - el acoso - que afecta especialmente a las mujeres. Con esto se quiere aportar a desnaturalizar comportamientos cotidianos que colaboran en sostener desigualdades en el espacio urbano y en el transporte, y por su intermedio, en el derecho a la ciudad.

\section{ABSTRACT}

This paper seeks to present and to make visible a form of citizen insecurity that has not been deeply analyzed: That which occurs in public transport. Although this kind of violence is a spatial and socioeconomic constraint that limits access to goods, services, activities and opportunities offered by cities to both women and men, it has among women different effects, considering their perceptions and experiences as two dimensions of insecurity. This article explores insecurity as a problem in public transport based on differences between insecurity perception and effective victimization of users (women and men) in the Metropolitan Area of Buenos Aires (AMBA), and then focusing on women's mobility strategies. The evidence is part of the "Ella se mueve segura" strategy, conducted in three Latin-American cities simultaneously: Buenos Aires, Quito and Santiago de Chile. The objective is to show insecurity on public transport as a gender restriction and as a form of violence that especially affects women (sexual harassment), contributing to the denaturalization of daily behaviors that sustain inequalities in urban space and transportation, and therefore, in rights in the city.

\section{RESUMO}

O trabalho busca visibilizar uma forma da insegurança cidadã ainda não analisada em profundidade: aquela no transporte público. Se bem a vulneração da segurança é um condicionante socioeconómico e espacial que limita o acesso aos bens, serviços, atividades e oportunidades oferecidas pelas cidades tanto a mulheres quanto a homens; sua percepção e experiência são duas dimensões da insegurança que têm um efeito diferente sobre as mulheres. A partir de uma exploração sobre as diferenças na percepção de insegurança e na efetiva vitimização de usuárias e usuários do transporte público na Área Metropolitana de Buenos Aires (AMBA), se indaga nas estratégias de mobilidade cotidiana das mulheres vinculadas com a insegurança como problema no transporte público. Apresenta-se evidência — baseada em informação primária quali-quantitativa e revelada no marco 
do estudo comparativo latino-americano "Ela Move-se Segura"- sobre o desempenho da insegurança como condicionante de gênero, e sobre uma forma de violência - $\mathrm{O}$ acosso- que afeta especialmente às mulheres, aportando a desnaturalizar comportamentos cotidianos que colaboram em sustentar desigualdades no espaço urbano e no transporte, e através dele, no direito à cidade.

\section{Planteo del problema}

Este artículo presenta evidencia cualicuantitativa sobre las percepciones y experiencias vinculadas con la inseguridad en el transporte público de las mujeres y varones del Área Metropolitana de Buenos Aires $(\mathrm{AMBA})^{1}$.

La reflexión no apunta a explicar la (in) seguridad en sí, sino a movilizar un ángulo de debate en torno al derecho a la ciudad, echando luz sobre aspectos poco visibles de uno de sus pilares analíticos, como es el transporte público (Habitat International Coalition, 2008).

La inseguridad urbana es un problema presente en el campo de los estudios de transporte y movilidad, pero de manera más bien colateral o complementaria que como foco de los análisis. Esto aplica incluso a la producción latinoamericana, donde la problemática es reconocida social y políticamente como de relevancia. La inseguridad vial, en cambio, sí se constituyó en las dos últimas décadas - o poco menos - en un eje central de la agenda, tanto académica, como técnica y política (Bardelli et al., 2016; Habitat III, 2015 a, b; Bottazzi et al., 2011).

Así, la inseguridad en el transporte público no ha sido analizada en profundidad, ni como una de las formas de vulneración de la seguridad ciudadana, ni como problema asociado con el uso del transporte público, con impacto en las prácticas de movilidad cotidiana y, por su intermedio, con el acceso a la ciudad.

La observación de las prácticas y estrategias de movilidad desplegadas por los usuarios y usuarias del transporte público potencia una reflexión sobre las relaciones de poder que se expresan en el espacio urbano (Jirón, 2007), muchas veces percibido como hostil por las mujeres (Soto, 2007; Zunino, 2014); y sobre las vinculaciones entre la movilidad cotidiana, el acceso y el uso diferencial de los espacios públicos y privados, según el género (Bourdieu, 1973; Rosaldo, 1974 en Segura, 2006).

Los relevamientos y estudios de transporte realizados a partir de los años 2000 confirman la vigencia de una regularidad no solo histórica sino también global: que la movilidad cotidiana de las mujeres es diferente a la de los varones, debido a sus actividades y roles de género en la estructura social (Breengaard et al., 2007; Díaz, 2002; ENMODO 2009-2010; Hanson, 2010; Massey, 1994; Quiros et al., 2014). Esto valida con evidencia actual una situación a la vez estructural e internacional, pero asimismo expresa un interés renovado por la problemática, que no solo abarca al
$\Longleftarrow$

Universidad de Buenos Aires. Correo electrónico: marinerome@gmail. com. ORCID: https://orcid. org/0000-0002-6888-4653

${ }^{1}$ El AMBA incluye a la Ciudad de Buenos Aires (CABA) y a 24 partidos conurbados que jurisdiccionalmente corresponden a la Provincia de Buenos Aires y componen el Gran Buenos Aires $(G B A)$.

territarias 39

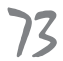


ámbito académico sino también incorpora a organismos de crédito con activa participación en la formación de la agenda de políticas públicas. El tratamiento del transporte público como elemento de inclusión social, desarrollo económico e igualador de oportunidades es transversal a la agenda de políticas urbanas a nivel mundial (Habitat, 2008, 2015 a, b), pero ahora se hace explícita su mención como facilitador de la participación de las mujeres en el mercado de trabajo, en cuanto estrategia para combatir la pobreza y promover el desarrollo de los países (Banco Mundial, 2010).

Sin embargo, las prácticas de movilidad de las mujeres aún no se han interrogado en profundidad, pensando en la mutua interacción entre la movilidad y el género (Law, 1999), o incorporando el análisis de sus implicancias sobre las oportunidades de realización de derechos ciudadanos - tanto en términos de accesibilidad como de acceso (Gutiérrez, 2016, 2011)—, o investigando incluso su heterogeneidad interna según la edad, etnia, nivel de ingresos económicos o habilidades (Díaz et al., 2007; Gutiérrez, 2015; Jirón, 2007).

Algunos estudios recientes caracterizan y diferencian los patrones de viaje de mujeres y varones con una perspectiva más amplia sobre la movilidad (Gutiérrez \& Reyes, 2017; Jirón et al., 2017), pero aún resta sumar la interacción entre sus percepciones y experiencias subjetivas, diferenciadas por medio del uso de los distintos transportes, y resta en particular recuperar al cuerpo físico de los sujetos móviles como categoría indisociable de sus prácticas (según Stanley, en Zunino, 2014). El cuerpo, en tanto mediación material por medio del cual opera la (re) creación de las identidades de género y que - en un proceso de repeticiones y disposiciones - arraiga las desigualdades que terminan por registrarse como "diferencias de naturaleza" entre los géneros (Bourdieu, 1998 en Cedillo, 2011), y se legitiman e institucionalizan.

Kessler (2012) entiende la inseguridad como toda amenaza 'consciente' a la integridad física - más que a los bienes-que puede abatirse sobre cualquiera. Genera un sentimiento que incluye el miedo al delito, pero también otro tipo de sensaciones, entre las que destaca la expectativa de victimización. Y a su vez, una serie de acciones individuales y colectivas para hacer frente a las amenazas percibidas. Por su parte, Lindón (2008) considera relevante incorporar a la reflexión la dimensión espacial de la "violencia/miedo", dada la interacción e influencia mutua entre los espacios de vida de los sujetos urbanos, y las relaciones sociales que en ellos tienen lugar y se desarrollan.

En este sentido, algunos autores sostienen que las propias percepciones de (in) seguridad tienen un efecto significativo sobre el uso de servicios de transporte (Delbosc et al., 2012), también sobre el uso diferencial de los espacios de la ciudad, y que particularmente las mujeres tienden a modificar o ajustar sus patrones de viaje al percibir mayor inseguridad (Kunieda et al., 2007).

Así, la inseguridad en el transporte público emerge como un fenómeno 
complejo, que condiciona el acceso a las oportunidades y que puede ser abordado según situaciones efectivas (experimentadas) o según percepciones, vinculadas con sentimientos de miedo o temor. Ambas con repercusión en la movilidad de mujeres y de varones, pero de manera diferenciada, y con implicancias también distintas, partícipes de procesos macro, atinentes a la construcción de la seguridad y de las desigualdades de acceso al espacio urbano y el transporte.

La construcción de la (in)seguridad -en tanto proceso accional y plural (Balzacq, 2010)_ requiere ser alumbrada por nuevas dimensiones, actores, objetos y contradicciones (Wilhelmsen, 2017; Baele \& Thomson, 2017). En estos términos, indagar en la inseguridad en el transporte público contribuye a re-problematizar la seguridad, incorporando no solo una dimensión o nuevo tema al análisis sino incorporándolo a la propia política de transporte público (y en especial, a su gestión) como parte activa en el entramado de esta problemática compleja y multidimensional.

El trabajo apunta, entonces, a reflexionar sobre la inseguridad en el transporte público buscando incorporar de manera preliminar dimensiones analíticas complejas y sensibles, como son la violencia y el miedo en ámbitos urbanos. Apunta asimismo a visibilizar acciones (de acoso, entre ellas) e indagar en su heterogeneidad aplicando un enfoque de género, para lo cual se recuperan las prácticas y estrategias de las mujeres usuarias del transporte público en el AMBA en contextos concretos, vinculados con su uso, e incluyendo aquel a bordo del vehículo.

Componer y definir qué es un enfoque de género es complejo dada su variabilidad histórica, social y geográfica, además de la propia del devenir del pensamiento. Es asimismo desafiante, y abre la posibilidad de reflexionar sobre las formas en la que los seres humanos son socializados y se construyen sus identidades como mujeres y varones, y cómo éstas se relacionan entre sí generando posiciones distintas (y desiguales) en la estructura social, que transforman las diferencias de sexo en categorías sociales. Es con este enfoque de género que el trabajo estudia la movilidad como práctica social (Gutiérrez, 2012) de uso del transporte público que implica la participación e interacción de ambos sexos en el espacio público (material y simbólicamente construido) (Lindón, 2011), y se pregunta por las percepciones y experiencias vividas en el cotidiano por mujeres y varones. Con respecto a la percepción de inseguridad y el miedo al delito, se recuperan las nociones de Jasso López (2015). La primera concebida como una 'preocupación social' que tiene la ciudadanía entorno a un determinado lugar o circunstancia. El segundo como aquella más específica que cada persona tiene sobre la posibilidad de ser víctima de un delito, a partir de información disponible. Este énfasis en la escala del análisis es una distinción metodológicamente útil. No obstante, el trabajo entiende que ambas nociones están mediadas por la subjetividad de la persona en un contexto sociohistórico y territorial determinado. territorios 39

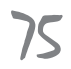


${ }^{2}$ El estudio fue financiado por FIA Foundation y CAF Banco de Desarrollo de América Latina.

${ }^{3}$ Este articulo no trabaja con la información proveniente de las entrevistas en profundidad con actores sociales clave.

${ }^{4}$ No obstante, la heterogeneidad socioeconómica del amba, el eje norte muestra los valores más altos del suelo por metro cuadrado del aglomerado (Di Virgilio et al., 2009) y concentra la población de alto poder adquisitivo (Fernández, 2015). El eje sur, aquellos másbajosy la población más pobre. Yel eje oeste, una situación intermedia (Colella, 2013).

\section{tersitarias 39}

Conforme a lo expuesto, el artículo realiza inicialmente un diagnóstico macro sobre los patrones de movilidad de las mujeres y los varones en el AMBA, utilizando información de estadísticas oficiales y buscando vincular los motivos de viaje y los medios de transporte usados con los roles de género y la asignación de responsabilidades frente al trabajo doméstico no remunerado. Y luego, indaga en las percepciones y experiencias vinculadas con la inseguridad en el transporte público de las usuarias y usuarios, generando información primaria, observando aspectos sociodemográficos y económicos de los hogares e identificando y analizando las estrategias de las mujeres como rutinas adaptativas de manejo de la inseguridad que median en la efectivización de sus derechos ciudadanos. A continuación, se detallará la metodología.

\section{Metodología}

La información primaria utilizada por el trabajo forma parte de un estudio más amplio, denominado "Ella se mueve segura" 2 (Allen et al., 2017) realizado en paralelo en tres metrópolis de América Latina: Buenos Aires, Quito y Santiago de Chile entre 2016 y 2017.

El estudio aplicó una estrategia metodológica cualicuantitativa que incluyó una encuesta de interceptación en centros de transbordo del AMBA, grupos focales con usuarias y usuarios de transporte público y entrevistas en profundidad con actores sociales clave ${ }^{3}$.
La encuesta de interceptación se llevó a cabo en las Estaciones de Retiro, Once y Constitución, los tres centros de transbordo más importantes del AMBA, que se corresponden con los ejes principales de transporte (norte, oeste y sur) del aglomerado, y con la prevalencia de población residente de estratos socioeconómicos altos, medios y bajos, respectivamente ${ }^{4}$. Se efectuó un muestreo no probabilístico de 816 casos (789 efectivos: 410 varones y 379 mujeres). En este tipo de muestreo la selección de la muestra no es aleatoria sino basada en criterios de selección. Se consideraron cuotas según género, grupos de edad y eje socioespacial (norte, oeste y sur), y se definió como usuario del transporte público a aquel que lo utiliza al menos 1 vez por semana. La variable género se indagó conforme a la autodefinición de la persona encuestada y previendo tres categorías: mujer, varón y una tercera categoría para respuestas distintas a las anteriores. El formulario incluyó 36 preguntas, divididas en 3 módulos: (i) sociodemográfico, (ii) movilidad cotidiana, (iii) percepción y experiencias de inseguridad en el transporte público. El periodo de relevamiento fue el mes de diciembre de 2016 (con excepción de las festividades de Navidad y año nuevo).

Inicialmente, se previeron tres grupos focales: uno mixto (varones y mujeres) en la Ciudad de Buenos Aires (CABA) y dos de mujeres residentes en el Gran Buenos Aires (GBA) Norte y Sur, respectivamente. Tras realizar el grupo mixto, surgió la necesidad de profundizar la indagación sobre 
las mujeres, para cotejar si la presencia de varones impactaba en la dinámica grupal. Por esta razón, se agregó uno nuevo solo de mujeres residentes en la CABA. En total, participaron de esta etapa cualitativa de recolección de datos, 33 usuarios del transporte público: 28 mujeres y 5 varones. De ellos, 17 eran residentes en la CABA y 16 en el GBA.

Asimismo, se analizaron datos secundarios provenientes de la última encuesta de movilidad domiciliaria realizada para el AMBA (ENMODO, 2009-2010), a fin de diagnosticar los patrones generales de la movilidad cotidiana de mujeres y varones a nivel macro o metropolitano.

\section{Contexto macro}

\section{de interpretación: ¡̨cómo y por qué se mueven las mujeres en el AMBA?}

Según el último Censo Nacional de Población, Hogares y Vivienda (2010), en el AMBA residen un total de 12806866 de personas, alrededor de 2800000 en la CABA y 9900000 en los 24 partidos que componen el GBA; concentrando así en su territorio al $32 \%$ de la población total del país y convirtiéndose en el área urbana de mayor tamaño del territorio argentino, donde se produce alrededor del $40 \%$ del PBI nacional.

De acuerdo con datos de la ENMODO (2009-2010), en el AMBA se realizan 19 millones de viajes diarios, de los cuales el $49 \%$ son en transporte público. El autotransporte (denominado comúnmente 'colectivo') es el modo público más utilizado: en la CABA, casi 8 de cada 10 viajes en transporte público son en colectivo; y en el GBA, casi 9 de cada 10 viajes. El segundo modo público es el ferrocarril de superficie, en el GBA; y el subterráneo, en la CABA.

En el AMBA las mujeres realizan, en promedio, más viajes diarios $(2,44)$ que los varones $(2,30)$, aun cuando la proporción de personas que viajan sobre las que no lo hacen es similar para ambos géne$\operatorname{ros}(50 \%)$. Asimismo, las mujeres utilizan principalmente los modos públicos (casi el $50 \%$ de sus viajes son el colectivo, tren o subte) y los no motorizados (un tercio de sus viajes, son a pie) (figura 1).

Los motivos de viaje de varones y mujeres muestran correlato con los roles construidos y ejercidos social y culturalmente. Del total de viajes realizados por las mujeres en el AMBA, la mitad son por trabajo $(27 \%)$ y estudio $(25 \%)$, mientras que estos motivos explican más de 7 de cada 10 viajes del total realizado por los varones $(48 \%$ trabajo y $25 \%$ estudio) (figura 2 ). En tanto, el tercer motivo de viaje entre las mujeres es dejar o recoger alguien del hogar de algún establecimiento educativo (13\% del total de viajes realizados por mujeres), y entre los varones es realizar compras $(4,9 \% \mathrm{del}$ total de viajes realizados por hombres).

$\mathrm{Al}$ analizar el reparto del total de viajes realizados por mujeres y varones según cada motivo (figura 3 ), se observa que las mujeres realizan algo más de un tercio del total de viajes por trabajo en el AMBA. Y que los viajes por estudio se reparten por partes iguales (mitad para cada sexo, aproximadamente). Al observar los territarias 39

77 
Figura 1. Reparto modal de viajes de mujeres y varones en el AMBA (en \%)

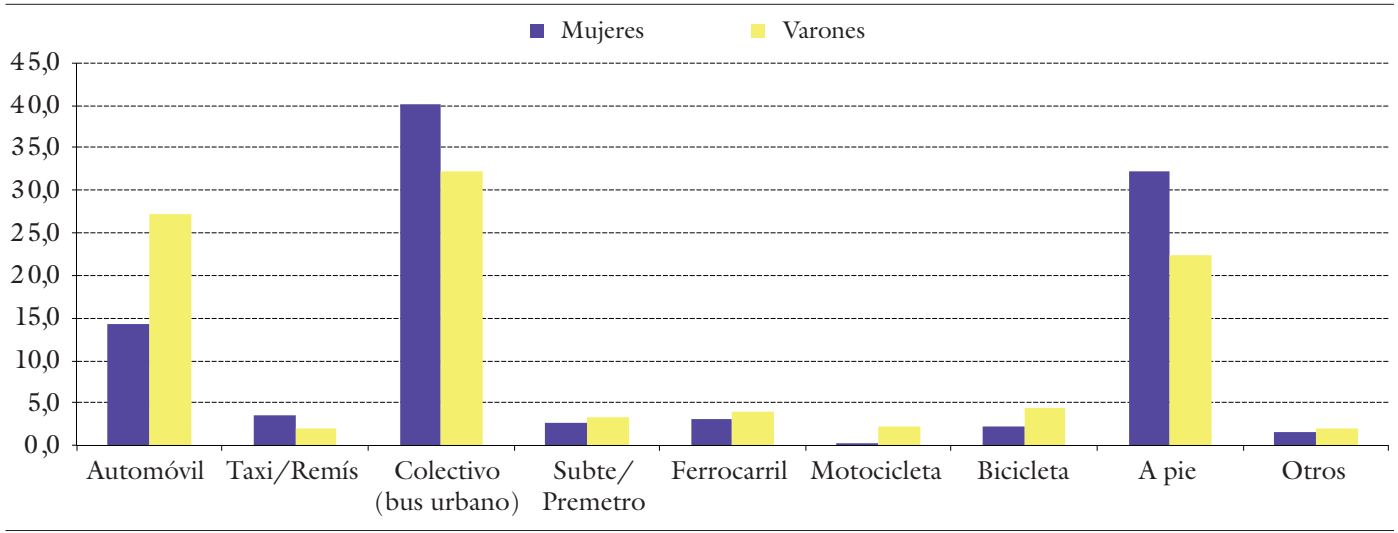

Fuente: elaboración propia con base en datos de ENMODO (2009-2010).

Figura 2. Reparto de los motivos de viaje de mujeres y varones en el AMBA vw(en \%)

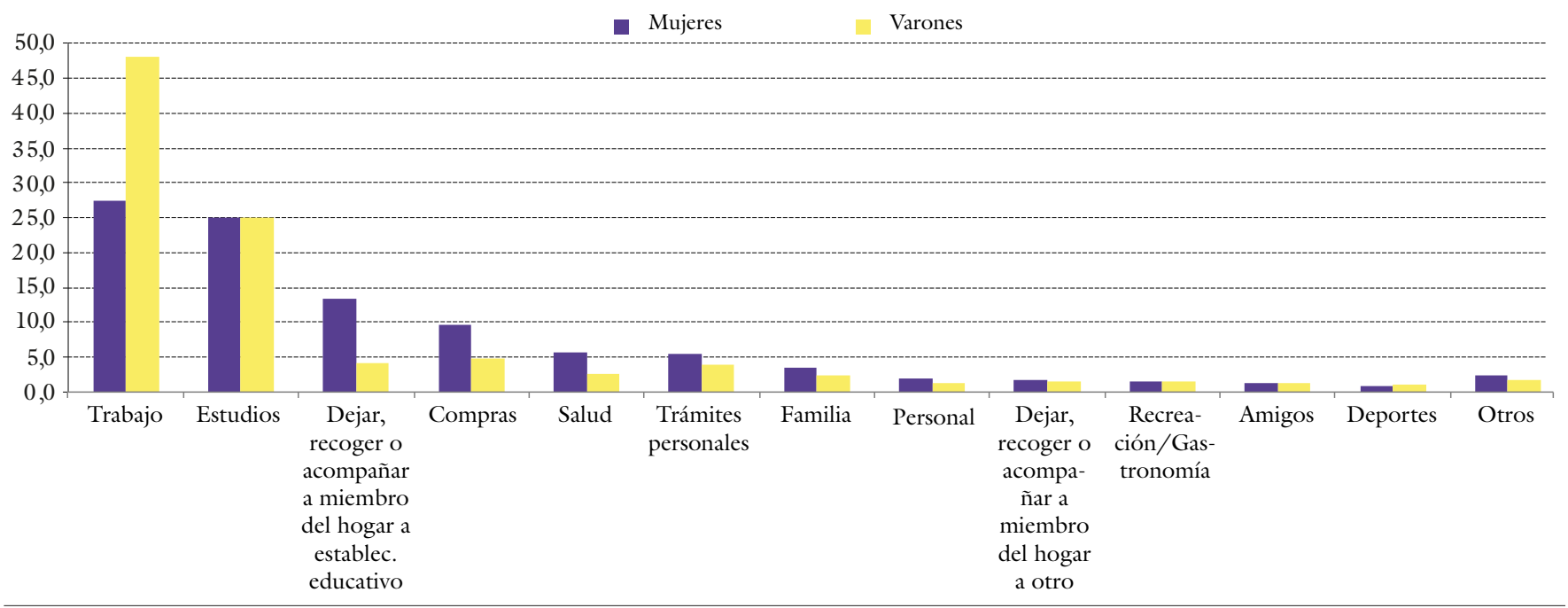

Fuente: elaboración propia con base en datos de ENMODO (2009-2010).

territarios 39 78 motivos de viaje que siguen en importancia tanto para mujeres como por varones (dejar o recoger alguien del hogar de algún establecimiento educativo, salud, compras), emerge de manera notable que las mujeres realizan alrededor del $70 \%$ del total $(78 \%$, $69 \%$ y $68 \%$, respectivamente).

La distribución de los motivos de viajes según sexo corrobora para el AMBA la cuestionada pero vigente identificación de los 
viajes con roles 'productivos' (realizados por varones) y 'reproductivos' (realizados por mujeres). Según Joan Scott (1993), los roles diferenciados según sexo son una construcción discursiva iniciada en el siglo XIX — a la que denomina ideología de la domesticidad-, mediante la cual se produce, sostiene y perpetúa la división sexual del trabajo a partir de la legitimización e institucionalización de diferencias biológicas y funcionales entre varones y mujeres. Esta 'artificial' división de roles muestra, sin embargo, estar profundamente arraigada en el AMBA, según esta simple pero reveladora lectura de los patrones de movilidad de varones y mujeres según motivos de viaje, no obstante dejar por fuera otros factores de relevancia (sociodemográficos, culturales, espacio-temporales y urbanísticos, entre otros) (Díaz, 2007; Hanson, 2010).

En la Argentina, la participación de las mujeres en el trabajo doméstico no remunerado muestra a nivel nacional que, independientemente de la edad, casi 9 de cada 10 mujeres se ocupan de los quehaceres domésticos y del cuidado de niños, enfermos o adultos mayores miembros del hogar (INDEC, 2013). Entre los varones esta participación alcanza a 5 de cada 10 . $\mathrm{Y}$ en términos del tiempo promedio diario dedicado, las mujeres dedican 3 horas diarias más $(6,4$ horas) que aquellos varones que participan de estas tareas ( 3,4 horas).

Cabe destacar asimismo que la participación en las tareas domésticas no presenta variaciones importantes según la condición de ocupación de las mujeres en el mercado laboral, no obstante haberse incrementado en los últimos años.

En síntesis, los patrones de viaje en el AMBA muestran que las mujeres viajan más, por motivos más diversos (y por ende a más lugares), usando medios de transporte con menor flexibilidad y autonomía de movimiento. El uso predominante de los modos públicos implica una mayor dependencia de los esquemas y calidades del servicio, y la elevada proporción de viajes a pie (cerca

Figura 3. Participación de varones y mujeres por motivos de viaje, en el AMBA (en \%)

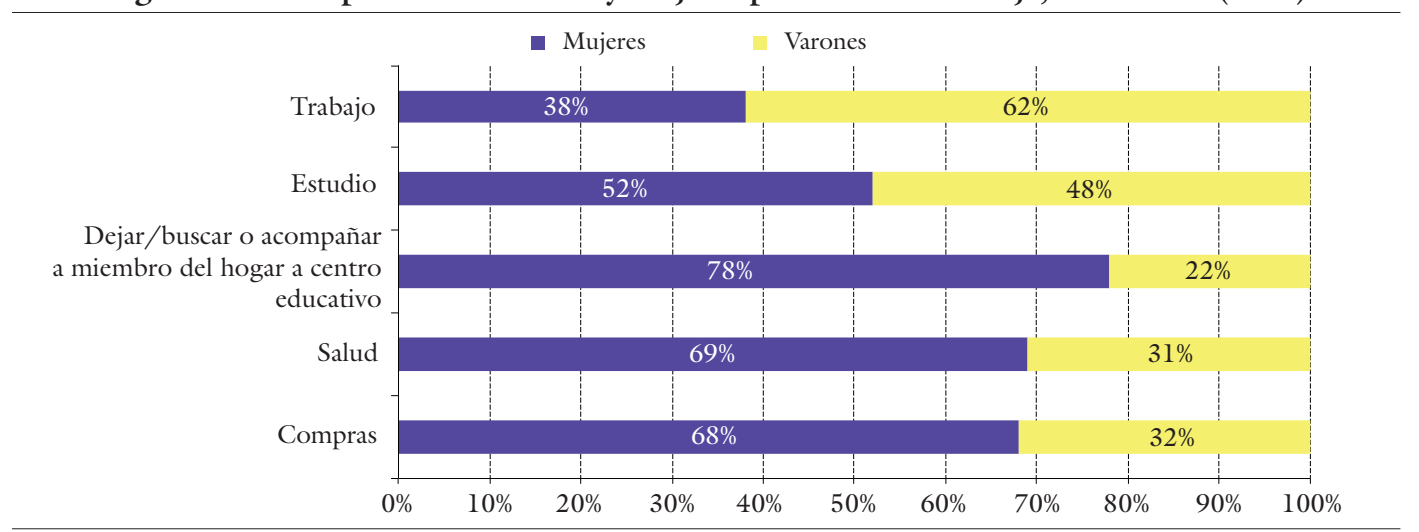

Fuente: elaboración propia con base en datos de ENMODO (2009-2010). 
${ }^{5}$ A valores corrientes de diciembre de 2016, $\$ 9000$ equivalen a 500 dólares.

${ }^{6}$ A valores corrientes de diciembre de 2016, $\$ 9000$ equivalen a 1100 dólares.

\section{territarias 39}

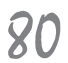

de un tercio de los viajes de las mujeres) implica alcances restringidos en términos de distancia. Así, el uso del transporte evidencia necesidades diferenciadas de movilidad de varones y mujeres, a la vez que expresa y reproduce formas desiguales de satisfacerlas, que indican limitaciones con impacto en la forma y el alcance con que las mujeres acceden a los bienes, servicios y oportunidades de la ciudad.

\section{La inseguridad en el transporte público: primer esbozo de un fenómeno complejo}

“[...] Es que está normalizado, es decir, vos ya vas por la calle y te gritan de todo ¿por qué en el transporte público no va a pasar lo mismo? Si hay total impunidad a que te digan cualquier guarangada $[\ldots]$ " (Testimonio de una mujer. Grupo Focal, “Ella se mueve segura" 2016-2017).

Los resultados de la encuesta de interceptación muestran que el $64 \%$ de los usuarios se sintieron inseguros en el transporte público. $\mathrm{Al}$ analizar esta percepción según sexo, los valores crecen entre las mujeres: 7 de cada 10 afirman haberse sentido inseguras (figura 4).

Se observan, asimismo, diferencias entre las propias mujeres, conforme al maternaje, a la edad y al nivel de ingresos del hogar al que pertenecen. Entre aquellas usuarias con hijos menores de 15 años, la sensación de inseguridad en el transporte público asciende al $78 \%$. El $60 \%$ de las mujeres que afirman haberse sentido inseguras tiene entre 18 y 40 años, y el
Figura 4. Percepción

de inseguridad de mujeres y varones

en el transporte público del AMBA (en \%)

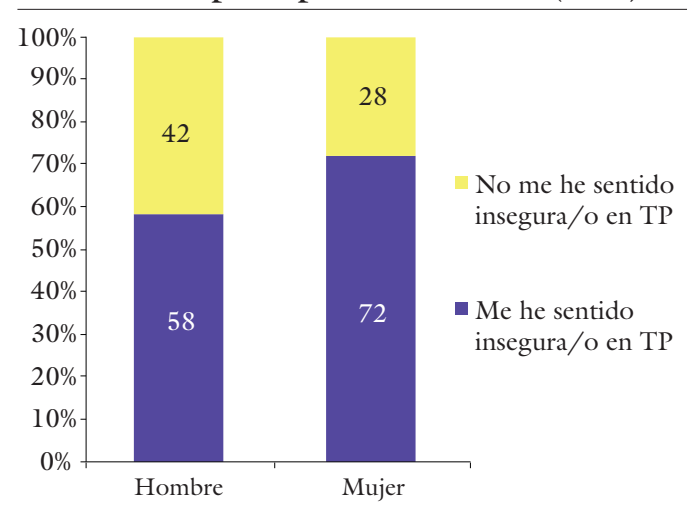

Fuente: elaboración propia con base en los datos de la encuesta de "Ella se mueve segura" (АMBA, 2016-2017).

$36 \%$ pertenece a hogares con el menor nivel de ingresos de la muestra (menos de 9000 pesos argentinos mensuales ${ }^{5}$ ), en tanto el $14 \%$ corresponde a los de mayores ingresos (más de 20001 pesos argentinos mensuales $\left.{ }^{6}\right)$.

En la tabla 1 se observan los aspectos que generan sensación de inseguridad en el transporte público, en orden de importancia. Los cinco primeros son mencionados convergentemente por usuarios y usuarias: cuando está oscuro $(17,8 \%)$, mucha gente dentro del colectivo/vagón (16,5\%), la caminata hacia la parada o estación (13,2\%), poca gente dentro del colectivo/vagón o en la parada/estación (13\%) y viajar con un niño o adulto mayor (10\%). En conjunto, reúnen el $70 \%$ de las menciones. En todos estos aspectos, el porcentaje de menciones es algo mayor en varones que en mujeres. La impronta varía, sin embargo, 
Tabla 1. Aspectos que generan sensación de inseguridad en el transporte público (en \%)

\begin{tabular}{|c|c|c|c|}
\hline Aspectos & Total & Varones & Mujeres \\
\hline $\begin{array}{l}\text { Cuando está oscuro } \\
\text { porque es de noche }\end{array}$ & 17,8 & 18,6 & 17,3 \\
\hline $\begin{array}{l}\text { Mucha gente que viaja } \\
\text { dentro del colectivo/ } \\
\text { vagón }\end{array}$ & 16,5 & 18,6 & 15,2 \\
\hline $\begin{array}{l}\text { La caminata hacia la } \\
\text { parada o la estación de } \\
\text { tren/subte (entorno, } \\
\text { iluminación) }\end{array}$ & 13,2 & 14,1 & 12,6 \\
\hline $\begin{array}{l}\text { Poca gente dentro } \\
\text { del colectivo/vagón, } \\
\text { pasillos, parada o } \\
\text { estación }\end{array}$ & 13,0 & 14,5 & 12,0 \\
\hline $\begin{array}{l}\text { Viajar con un niño o } \\
\text { adulto mayor }\end{array}$ & 10,0 & 10,8 & 9,4 \\
\hline $\begin{array}{l}\text { Los actos o palabras } \\
\text { de acoso de algún } \\
\text { desconocido }\end{array}$ & 9,7 & 7,3 & 11,3 \\
\hline $\begin{array}{l}\text { Cuando hay mayor } \\
\text { presencia de hombres }\end{array}$ & 8,1 & 4,7 & 10,4 \\
\hline $\begin{array}{l}\text { Viajar sola/o, sin } \\
\text { compañía }\end{array}$ & 6,3 & 4,7 & 7,3 \\
\hline Otra situación & 5,4 & 6,8 & 4,5 \\
\hline Total & 100 & 100 & 100 \\
\hline
\end{tabular}

Fuente: elaboración propia con base en datos de la encuesta de "Ella se mueve segura" (АМВA, 2016-2017).

en los aspectos siguientes: los actos o palabras de acoso (11,3\%), la mayor presencia de hombres $(10,4 \%)$ y viajar solo/a sin compañía $(7,3 \%)$ son más mencionados entre las mujeres. También varía en estos casos el orden de importancia: para las mujeres, los actos o palabras de acoso y la mayor presencia de hombres son aspectos que generan más sensación de inseguridad que el viajar con un niño o adulto mayor, o solas. En su conjunto, representan el $29 \%$ de las menciones entre las mujeres. En tanto para los varones, viajar solos o la mayor presencia de hombres son aspectos con importancia aún menor que aquellos agrupados como "otras situaciones", dada su poca participación sobre el total $(5,4 \%)$. La figura 5 permite observar con mayor claridad estas diferencias que expresan una impronta de género: las menciones de mujeres son mayoritarias con respecto a la mayor presencia de hombres $(77 \%)$, el viajar solo/a sin compañía (70\%) y los actos o palabras de acoso de algún desconocido $(70 \%)$.

También, emergen diferencias al observar la cantidad de aspectos que generan inseguridad al viajar en transporte público: la cantidad de aspectos es mayor entre las mujeres. Mientras que 6 de cada 10 usuarios a los que ningún aspecto les genera inseguridad son varones; 7 de cada 10 usuarios a los que cinco o más aspectos les generan inseguridad, son mujeres (figura 6).

Tanto la encuesta como los grupos focales abordaron la inseguridad diferenciando la percepción de la efectiva victimización de las usuarias y usuarios. Se registraron tres tipos de situaciones de inseguridad en el transporte público: los robos, las peleas y el acoso. A fin de analizar las diferencias según sexo, se agruparon aquellas vinculadas con robos y peleas, $y$ las situaciones de acoso. territarias 39 
Figura 5. Participación de varones y mujeres según aspectos que generan sensación de inseguridad en el transporte público en el AMBA (en \%)

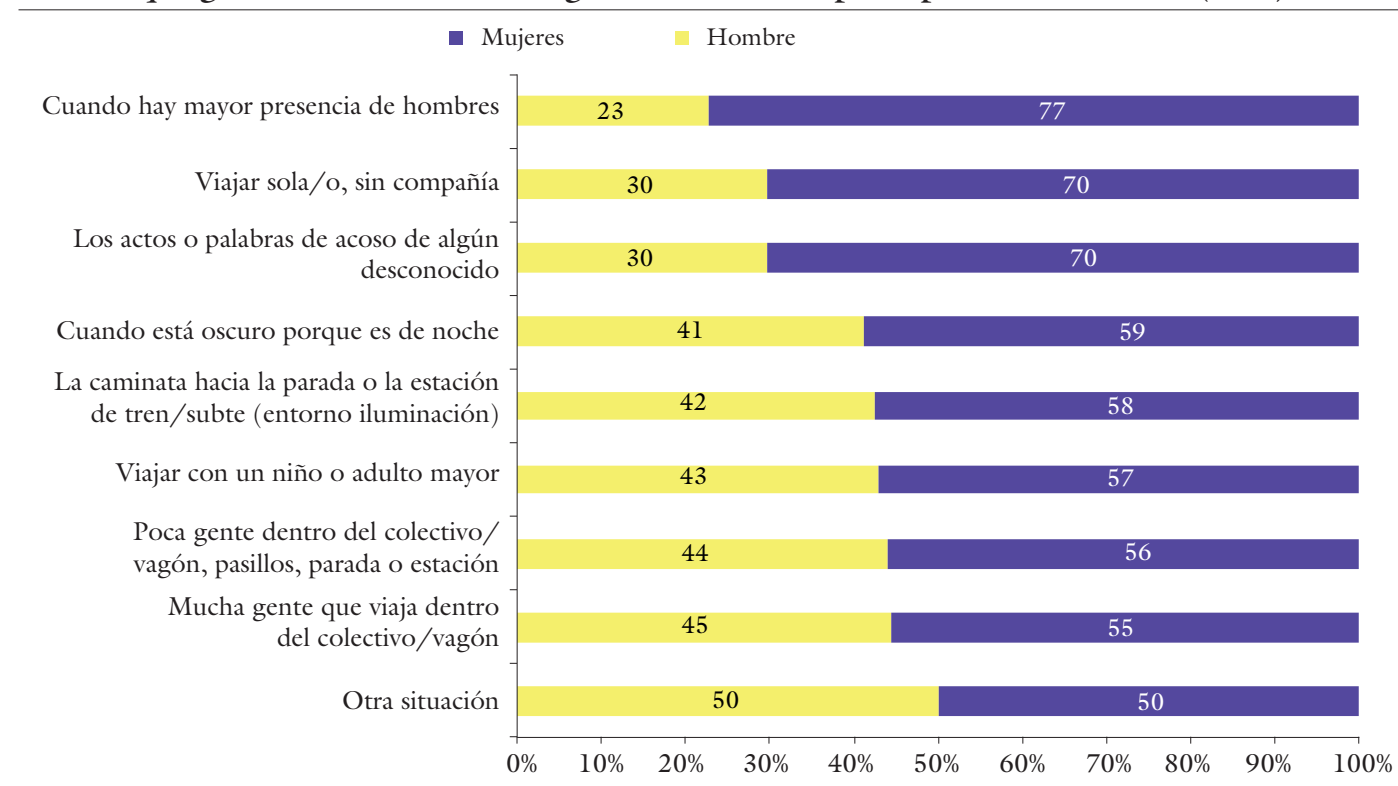

Fuente: elaboración propia con base en datos de la encuesta de "Ella se mueve segura" (AMBA, 2016-2017).

Figura 6. Cantidad de aspectos que generan sensación de inseguridad entre las/los usuarias/usuarios del transporte público (en \%)

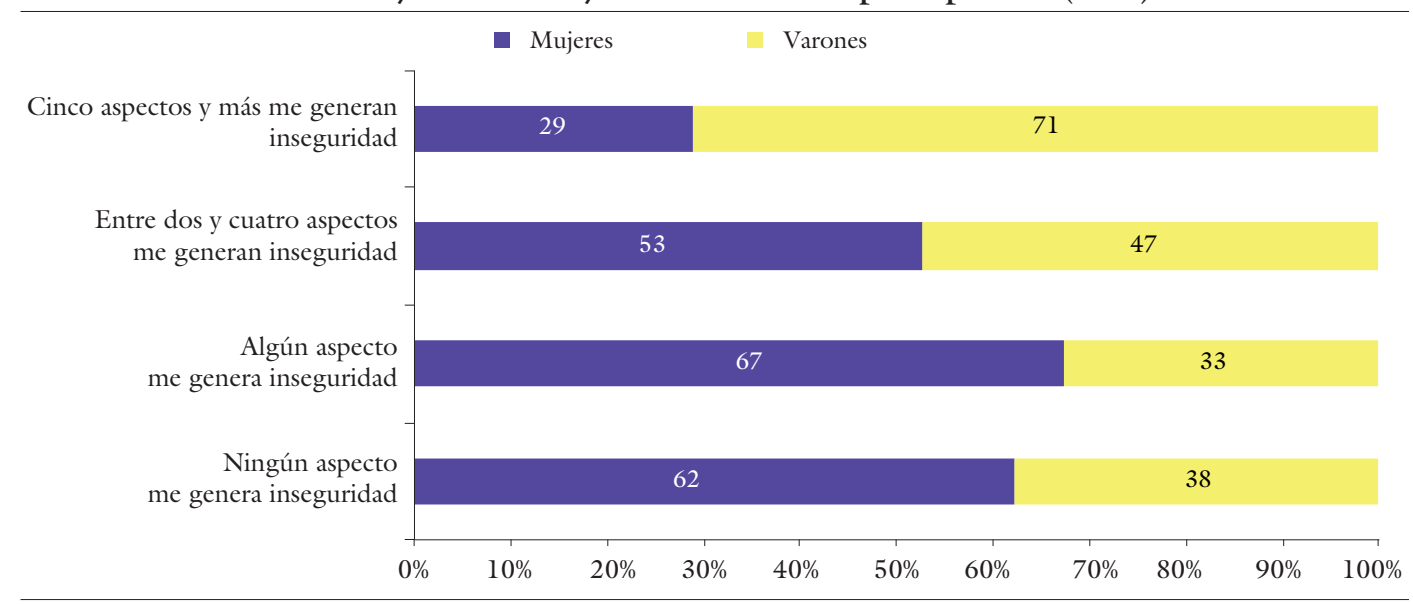

Fuente: elaboración propia con base en datos de la encuesta de "Ella se mueve segura" (AMBA, 2016-2017). 
Los resultados de la encuesta indican que la mayoría de los usuarios del transporte público vio situaciones de robos o peleas, así como de acoso en sus viajes durante el último año: el 86\% afirma haber visto alguna situación de robo o pelea, y el $71 \%$ situaciones de acoso. No hay diferencias de sexo en cuanto a los hechos vistos o presenciados, ya que el $48 \%$ y $47 \%$, respectivamente, corresponde a mujeres (figura 7 ).

Con respecto a las situaciones experimentadas, los robos y peleas se distribuyen de manera similar entre varones y mujeres: del $28 \%$ de los usuarios que afirma haber experimentado alguna situación de robo o pelea en el transporte público durante el último año, el $48 \%$ son mujeres. Estas situaciones incluyen el robo/hurto sin armas y sin violencia ( $59 \%$ ), el robo con armas $(17 \%)$, las peleas con golpes $(7 \%)$, los insultos o peleas con gritos y sin golpes $(17 \%)^{7}$. Pero cuando se trata de situaciones de acoso, sí se evidencian diferencias entre sexos: del $27 \%$ de los usuarios que afirma haber experimentado alguna situación de acoso en el transporte público durante el último año, el $73 \%$ son mujeres (figura 7). Se profundiza seguidamente en las situaciones de acoso.

\section{Inseguridad y situaciones de acoso en el transporte público}

“[...] Porque el abuso no es que violen a alguien, abuso es que un tipo se acerque a una mujer sin consentimiento [...]" (Testimonio de un varón. Grupo Focal, "Ella se mueve segura" 2016-2017).

La encuesta arroja que 153 de las 379 mujeres encuestadas experimentaron

Figura 7. Situaciones de inseguridad vistas (círculo externo) y experimentadas (círculo interno) en el transporte público durante los últimos 12 meses (en \%)

Situaciones de Acoso

Fuente: elaboración propia con base en la encuesta de "Ella se mueve segura" (AMBA, 2016-2017).

${ }^{7}$ Porcentajes para el total de mujeres que experimentaron situaciones de roboso peleas. Es importante tener en cuenta que la pregunta respecto a la experiencia de este tipo de situaciones es múltiple, de modo que cada encuestado podia elegir más de una categoría de respuesta. 
${ }^{8}$ La pregunta sobre la persona a quien avisó $y / 0$ ante quien realizó la denuncia fue de respuesta múltiple. Por ello, los porcentajes representan la cantidad de mujeres que mencionaron cada una de las categorías de respuesta, sin ser excluyentes las opciones.

"Elverbo "apoyar" se utiliza comúnmente en Buenos Aires para dar cuenta de las formas en que los pasajeros varones acosan a las mujeres acercando los genitales al cuerpo de las pasajeras (Zunino, 2012).

${ }^{10}$ Vale nota 5, considerando el total de mujeres que experimentaron situaciones de acoso.

\section{tersitarias 39}

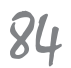

alguna situación de acoso en el transporte público en el AMBA durante el último año.

Asimismo, indica que el $90 \%$ de quienes experimentaron dos o más situaciones de acoso en el transporte público son mujeres, lo que las muestra proclives a situaciones de revictimización.

No obstante, solo el $44 \%$ de las mujeres que vieron o experimentaron situaciones de acoso en el transporte público avisaron sobre lo ocurrido: a la policía $(34 \%)$, al chofer o trabajador/a de la empresa (32\%), a los demás pasajeros (24\%) o a familiares $(9 \%)^{8}$. Esto es, más de la mitad de las mujeres no avisaron o comentaron lo ocurrido ni siquiera con su entorno más cercano.

Entre las situaciones de acoso se incluyen las siguientes: (i) un pasajero diciendo palabras obscenas/groseras de carácter sexual $(32 \%)$, (ii) un pasajero realizando manoseo y/o apoyo 9 de carácter sexual sobre el cuerpo $(26 \%)$, (iii) un pasajero tomando fotos al cuerpo sin consentimiento ( $5 \%$ ), (iv) un pasajero mostrando o exhibiendo sus genitales $(6 \%)$, (v) sintió que otro pasajero/a la/lo perseguía $(30 \%)^{10}$. Por medio de los grupos focales que abarcaron la trayectoria de vida de las participantes, sin acotar las experiencias al último año, se identificaron como tipologías principales: el apoyo y/o manoseo sobre el cuerpo, la exhibición de genitales, y las palabras obscenas, miradas lascivas, susurros.

Las 24 situaciones de acoso relatadas en los grupos focales ocurrieron a bordo del transporte público (solo en un caso durante la caminata al trasbordar de un medio a otro) y bajo circunstancias diversas, indistintamente: con el vehículo lleno o casi vacío, de madrugada, de día, de noche, viajando sentadas o paradas, solas o con sus hijos/as, familiares o amigas. Esto indicaría que las situaciones de victimización experimentadas tienen lugar bajo circunstancias aún más generales que aquellas más mencionadas entre las que generan sensación de inseguridad (tabla 1). Asimismo, el colectivo emerge como el modo público en el que más situaciones de acoso se experimentaron (figura 8). Esto podría deberse, no obstante, al hecho de que es el transporte más utilizado por las mujeres en el AMBA.

\section{Figura 8. Cantidad de situaciones de acoso relatadas por mujeres, según modo de transporte de ocurrencia}

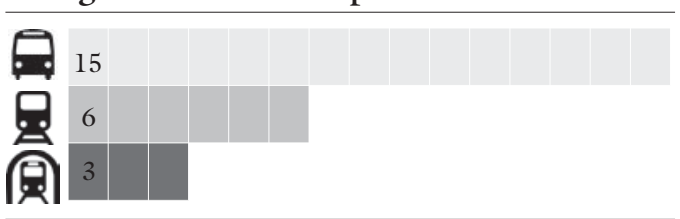

Fuente: elaboración propia con base en datos de grupos focales de "Ella se mueve segura" (AMBA, 2016-2017).

La reacción más frecuente de las mujeres ante este tipo de agresiones es "irse": a otro lado del coche, a otro vagón, o incluso descender del medio de transporte. La figura 9 muestra un orden de magnitudes en el que desciende la cantidad de menciones a medida que aumenta la actitud de exposición pública e involucramiento activo de terceros, llegando tal involucramiento a poder expresar la situación al conductor u otros pasajeros. 
Figura 9. Reacciones de las mujeres frente a situaciones de acoso experimentadas en el transporte público

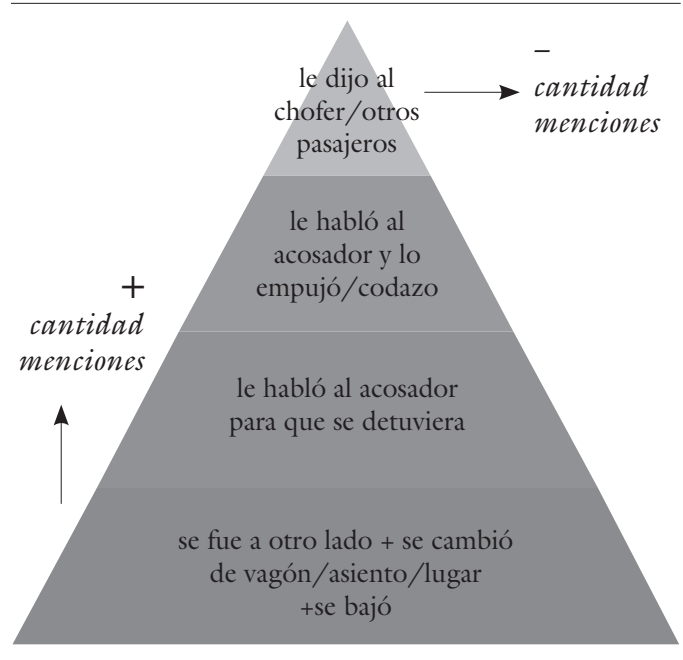

Fuente: elaboración propia con base en datos de grupos focales de "Ella se mueve segura" (АМВA, 2016-2017).

Con respecto a la realización de una denuncia formal de los grupos focales, se recoge la siguiente reflexión:

[...] como que la apoyada ya es algo natural, por eso nadie gasta tiempo o va a la comisaría porque ¿qué denuncia vas a hacer? ¿Qué vas a ir a decir? ¿Sí, mirá, hoy me subí al colectivo y un vago me apoyó? O sea, la realidad es que no te dan bola, te tratan mal, el mismo policía se va a reír en tu cara [...] (Testimonio de una mujer. Grupo focal, "Ella se mueve segura" 2016-2017).

Esta visión es transversal a los diversos perfiles socioeconómicos y etarios de las mujeres participantes, y está en consonancia con lo relevado en 2016 mediante el "Primer índice de violencia machista" elaborado por el colectivo $\mathrm{Ni}$ una menos, según el cual solo el $5 \%$ de las mujeres que sufrieron alguna situación de acoso callejero, realizaron la denuncia policial.

En cuanto a la actitud del acosador, se menciona que en general desciende del transporte, suele tratar de "loca" a la propia víctima o a quien lo hubiera puesto en evidencia, o directamente niega la situación. En cuanto a la actitud de los demás pasajeros, salvo excepciones, se menciona que no reaccionan, son espectadores: “[...] No siempre, pero en general la gente te mira y sigue con los auriculares [...]" (Testimonio de una mujer. Grupo focal, "Ella se mueve segura" 2016-2017). Esta tendencia a una actitud pasiva frente a situaciones de acoso en el transporte público va en sintonía con lo relevado por el CINEA (Untref, 2016) mediante una encuesta realizada a varones y mujeres residentes en el AMBA, según la cual apenas el $51 \%$ afirma que ante una situación de violencia de género, intervendría y denunciaría el hecho ante la policía.

La sensación que más mencionan las mujeres tras experimentar una situación de acoso, es la vergüenza (figura 10). Esto puede responder a la percepción de una 'falta propia', como también a la de ser 'receptora de una acción humillante', lo cual sugiere un aspecto de interés para una indagación mayor, fuera del alcance de este estudio. Lo que sí fue posible identificar, es que el conjunto de sensaciones mencionadas indica un reconocimiento muy tangible de un comportamiento sancionable. Zunino (2014) señala que muchas 
de las situaciones de abuso o acoso que viven cotidianamente las mujeres en el transporte público no implican solo un modo de apropiarse del cuerpo del otro, sino también de marcar un 'fuera de lugar'. Las sensaciones experimentadas por las mujeres denotan que el transporte público no es un espacio neutro ni neutral, sino que expresa y contiene relaciones sociales que refuerzan y reproducen desigualdades, entre ellas, las de género.

Figura 10. Sensaciones mayormente mencionadas por las mujeres al experimentar acoso en el transporte público

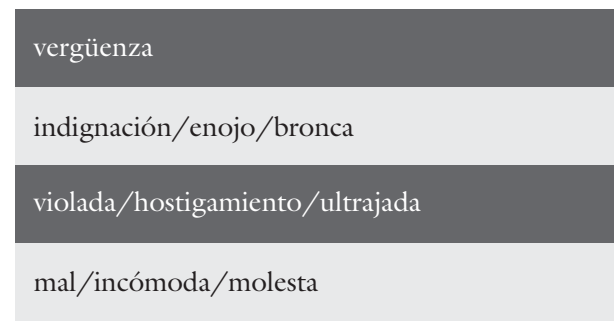

Fuente: elaboración propia con base en datos de Grupos focales de "Ella se mueve segura" AMBA, 2016-2017.

\section{Inseguridad y aspectos del servicio de transporte público}

“[...] También te preocupa la integridad física cuando viajás, por el aire o porque el colectivo va muy rápido, porque no tenés dónde meterte. A mí me ha pasado de tener que bajarme del subte porque no podía respirar $[\ldots]$ " (Testimonio de una mujer. Grupo focal, "Ella se mueve segura" 2016-2017).

Se identificaron tres momentos del viaje distintos según las situaciones potenciales de inseguridad percibidas: la caminata, la espera y a bordo del vehículo. Estos momentos son habitualmente reconocidos por los estudios y las políticas de transporte para la estimación del tiempo de viaje. Sin embargo, profundizar en las percepciones y experiencias de los usuarios permite visibilizar el papel del transporte público (y en particular, de la gestión operativa del servicio) en la construcción procesual y accional de la inseguridad, su interacción con el espacio público y sus implicancias en la (re) producción de desigualdades urbanas, de acceso a la ciudad en general y de género en particular.

El momento de la caminata hasta o desde las paradas o estaciones del transporte público, al igual que el de la espera, está atravesado por miedos ante una diversidad de situaciones potenciales que pueden ocurrir en el espacio público, y que emergen como una preocupación extra, asumida (y naturalizada) como parte del viaje cotidiano: "[...] Es re normal ir por la calle caminando y estar pendiente de quién va pasando y pasa un auto y te grita algo y después tenés miedo de que te esté siguiendo $[\ldots]$ " (Testimonio de una mujer. Grupo focal, "Ella se Mueve Segura" 2016-2017).

La espera en la parada o estación del transporte público conlleva sentir desprotección, particularmente, en las mujeres, y en especial durante las horas en las que no hay luz del día, o cuando el entorno no está bien iluminado. El hecho de que haya otras personas esperando es percibido como un atenuante, pero sin dejar de ser 


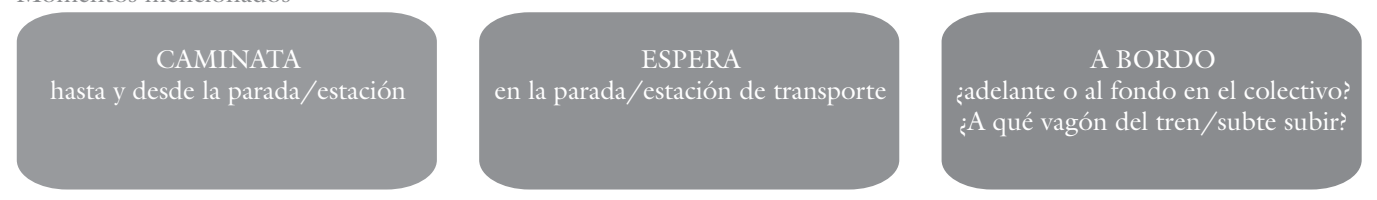

Fuente: elaboración propia con base en datos de Grupos focales de "Ella se mueve segura" AMBA, 2016-2017.

un factor de preocupación. Esto se vincula con las reacciones que podrían tener los desconocidos frente a una situación que requiriese de su ayuda: "[...] todas estas preocupaciones están, en la parada, sola o con personas que no conocés, que si viene alguien por ahí la gente suele ser egoísta o no suele actuar, cuando pasa algo la gente suele correr y por ahí te deja sola, la gente no sabe reaccionar, yo tampoco sabría, yo me hago la viva pero tampoco sabría $[\ldots]$ "... (Testimonio de una mujer. Grupo focal, "Ella se Mueve Segura” 2016-2017).

Las mujeres no manifiestan miedo a la situación de estar solas en sí, sino a la posibilidad de que les pase algo en la parada, que está desolada. Ese algo, definido de manera difusa como un "no sabés lo que te puede pasar" (Testimonio de una mujer. Grupo focal, "Ella se mueve segura" 20162017), incluye temores diversos: ante un potencial ataque sexual, robos, a estar con personas desconocidas, o a que les griten cosas. Una de las participantes de los grupos focales señala: “[...] me ha pasado de estar esperando al colectivo y que pare un auto y haya un señor masturbándose [...]" (Testimonio de una mujer. Grupo focal, "Ella se mueve segura", 2016-2017).
El amplio y difuso espectro de situaciones que abarca la percepción de inseguridad durante la caminata o la espera del transporte público podría leerse, siguiendo a Bergman et al (2009), en clave de un proceso que des-identifica las figuras del temor de las imágenes más estigmatizadas, y expande la percepción de inseguridad como criterio de evaluación del mundo por medio de categorías de amenaza de diverso tipo.

Ahora bien, al llegar el vehículo del transporte público a la parada o la estación, disminuyen unas preocupaciones, pero se encienden otras, en especial entre las mujeres: aquellas identificadas con un tercer momento del viaje, que remite al durante, esto es, al momento a bordo del transporte público.

Las estrategias relatadas por las usuarias permitieron identificar medidas y rutinas personales de manejo de la inseguridad. Subir al colectivo, al tren o al subte implica para las mujeres observar previamente si el vehículo está vacío o si hay mucha gente, si hay mayoría de varones o, si es que hay pocos, ver dónde se ubican. Estos criterios se usan para evaluar qué acciones tomar al abordar. Una estrategia mencionada en territarias 39 
general durante los grupos focales es ubicarse en la parte trasera del vehículo para visualizar de manera amplia lo que ocurre y así poder anticiparse de manera defensiva.

Reconstruir la situación a bordo permitió asimismo identificar diferencias con los momentos anteriores, dado que esta se percibe como una obligada y a la vez restringida físicamente. Una usuaria menciona:

[...] capaz que en la calle lo que pasa es que, si ves algo que no te gusta, estás pasando y ves a un tipo decís bueno, cruzo la calle o doblo en esta esquina, en cambio en el colectivo, [en] el transporte no podés hacer eso, tenés que quedarte, o a menos que te sientas muy incómoda y te bajes y esperes otro colectivo $[\ldots]$ (Testimonio de una mujer. Grupo focal, "Ella se mueve segura" 2016-2017).

Posiblemente, esto explica la alta correlación entre las preocupaciones y las estrategias a bordo, dado que son una adaptación ineludible para efectivizar el uso del transporte público.

Como se mencionó, el transporte público más utilizado en el AMBA es el colectivo, y en especial por las mujeres. El rol del conductor frente a situaciones de inseguridad es percibido de distintas maneras. Por un lado, su presencia es señalada como un atenuante, por ser un potencial referente a quién acudir, a diferencia de lo que ocurre en trenes y subterráneos, en los que no se identifican responsables del servicio de manera clara y

\section{territarias 39} 88 continua. Por el otro, el hecho de que los conductores sean varones es señalado (por mujeres y varones) como una desventaja frente a la ocurrencia de situaciones - fundamentalmente de acoso- que afecten a mujeres, adolescentes y/o niñas: “[...] el que tiene que mediar es un varón y es muy indiferente [...]" (Testimonio de un varón. Grupo focal, "Ella se mueve segura" 20162017).

Las preocupaciones vinculadas con la inseguridad y asociadas con los momentos de la espera y a bordo del transporte público aportan información sobre aspectos que hacen a la gestión operativa del servicio, y no son solo repercusiones de la inseguridad urbana en general, forma en la que habitualmente es visto el problema por los estudios o políticas sectoriales, como uno ajeno y que excede al propio servicio.

Por medio de la información cualitativa, se identifican preocupaciones vinculadas con la incertidumbre en el momento de la espera $-\mathrm{O}$ previo al abordaje-, y vinculadas con la integridad física en el momento a bordo (figura 12).

La incertidumbre es el primer factor que incide en las prácticas de movilidad de las mujeres al salir de su hogar para realizar actividades. La información sobre el servicio (o su confiabilidad) se constituye como un elemento clave en interacción con la percepción de inseguridad y las preocupaciones de las usuarias: conocer dónde es la parada del colectivo, la frecuencia del servicio o si ocurrió alguna modificación en el recorrido, repercute en sus prácticas, y son todos aspectos íntimamente ligados con las condiciones en que se brinda el servicio público de transporte. 
A bordo del transporte público se activa otra preocupación (figura 13), que se percibe de manera amplia como la integridad física, y que también está ligada a las condiciones de prestación del servicio. Se incorporan inquietudes sobre el nivel de ocupación de los coches y vagones, sobre su antigüedad y mantenimiento, y sobre las formas de manejo de los conductores.

En líneas generales, emerge en los grupos focales que las preocupaciones de varones y mujeres vinculadas con la inseguridad en el transporte público resultan dependientes de otras variables, entre ellas: del horario del viaje (si son horas pico, muy tempranas por la mañana o muy tardes en la noche), del día de la semana (si es laboral, fin de semana o feriado) y de la zona del viaie (conocida o desconocida).

\section{Inseguridad en el transporte público: vislumbrando efectos}

[...] Ser mujer también es el arte de planificar absolutamente todo. De hecho, es algo con lo que vivo peleando. Vos varón no peleás, nunca te planteaste si un día te intentan violar, no te lo planteaste nunca, jamás, y yo cuando vuelvo a la noche a mi casa y sí, lo tengo que pensar todos los días, y fijarme para dónde tengo que correr [...] (Testimonio de una mujer. Grupo focal, "Ella se mueve segura" 2016-2017).

Las situaciones de inseguridad vistas o experimentadas en el transporte público impactan en las prácticas de movilidad de los usuarios. El $27 \%$ de los encuestados,

Figura 12. Preocupaciones previas al abordaje = incertidumbre

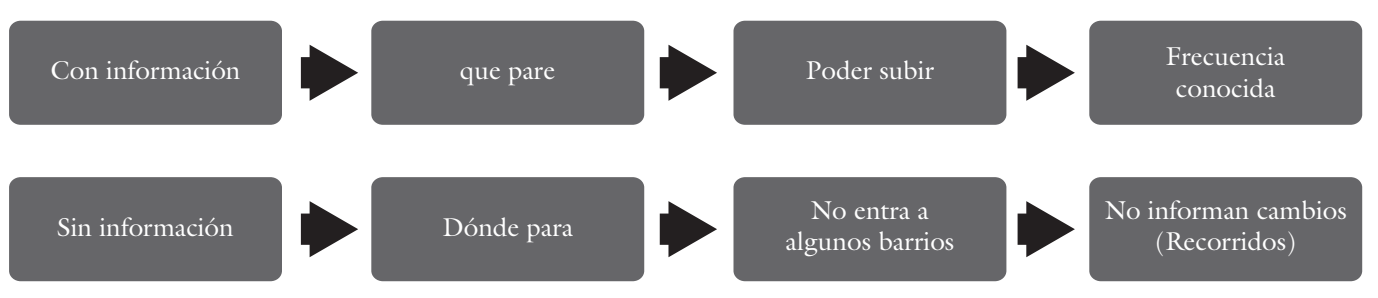

Fuente: elaboración propia con base en datos de Grupos focales de "Ella se mueve segura" AMBA, 2016-2017.

Figura 13. Preocupaciones a bordo $=$ integridad física

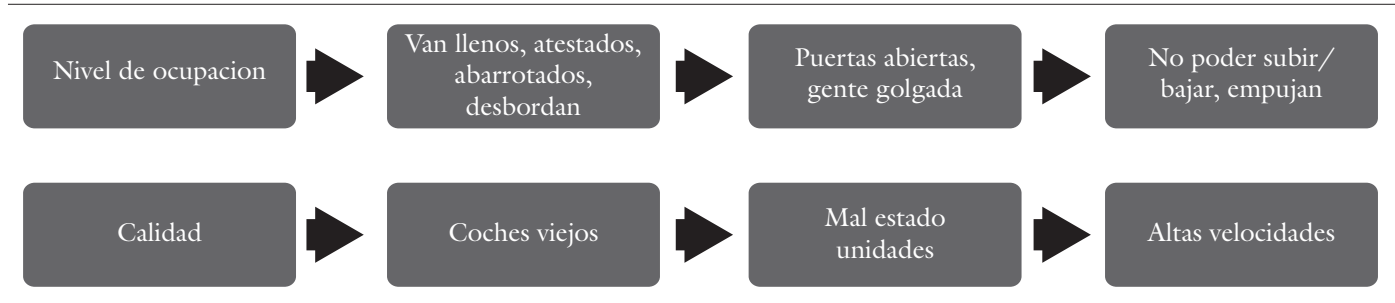

Fuente: elaboración propia con base en datos de Grupos focalẹs de "Ella se mueve segura" AMBA, 2016-2017. 
tanto mujeres como varones, afirma haber modificado sus decisiones de viaje tras escuchar, ver y/o experimentar situaciones de acoso, robos o peleas. De estos, el $62 \%$ son mujeres, porcentaje que trepa al $80 \%$ tras haber sido víctimas de situaciones de acoso de manera efectiva.

Las situaciones vistas o experimentadas retroalimentan el miedo y la percepción de inseguridad, con mayor impacto entre las mujeres: el $75 \%$ de aquellas que vieron o experimentaron una o más situaciones de acoso, robos o peleas, mencionan haberse sentido inseguras al utilizar el transporte público.

La mayor inclinación de las mujeres a modificar sus decisiones de viaje cuando entra en juego la inseguridad, encuentra correlato en el conjunto de estrategias que despliegan para resguardarse: “[...] para mí no hay prueba más evidente de que viajar es distinto para una mujer que para el hombre si uno considera todas las variables que ponemos en práctica a la hora de subirnos a un transporte público [...]" (Testimonio de una mujer. Grupo focal, "Ella se mueve segura" 2016-2017). El abanico es amplio y abarca tanto la planificación como la realización del viaje en sí, el momento previo al abordaje como a bordo del transporte público, y se priorizan las acciones defensivas (figura 14).

Las prácticas y estrategias de las mujeres permiten identificar acciones de securización, con implicaciones a la vez diversas e invisibilizadas. Estas expresan adaptaciones que habilitan alternativas frente a las dificultades que vivencian y que agregan una carga a lo cotidiano (en tiempos, costos, esfuerzos de organización), que a su vez tensiona con el derecho a un ejercicio pleno de sus libertades y autonomías personales (Naredo 1998, en Falú, 2009), y con un acceso equitativo a las oportunidades urbanas (bienes, servicios, actividades y relaciones sociales, familiares, laborales, etc.).

\section{Conclusiones}

La información cualicuantitativa generada por este trabajo permite brindar un diagnóstico sobre la inseguridad en el transporte público del AMBA, un problema inexplorado como tal hasta el momento. Este es su aporte primario. Contribuir a colocar la inseguridad como problema del y en el transporte público. Y al transporte público como problema de la inseguridad urbana.

Abordarlo permite incorporar a la reflexión la dimensión de la violencia/miedo, aunque sea de un modo preliminar: las prácticas y estrategias vinculadas con el uso del transporte público en el AMBA y a bordo de este, revelan rutinas personales (y familiares) de manejo de la inseguridad.

Es dable considerar la utilidad metodológica de operacionalizar la violencia/ miedo haciendo una distinción entre la percepción (como preocupación de nivel colectivo) y la experiencia de situaciones de inseguridad, dado que ambas dejan ver panoramas diferentes. Se observa una interacción entre percepciones y experiencias subjetivas, y asimismo una retroalimentación, especialmente entre las mujeres. 


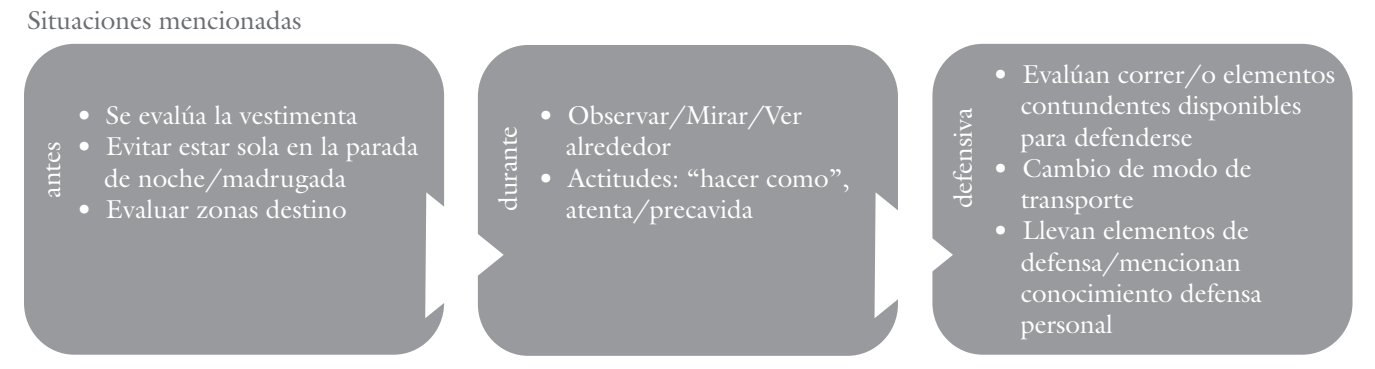

Fuente: elaboración propia con base en datos de Grupos focales de "Ella se mueve segura" AMBA, 2016-2017.

De manera emergente, se identifican dos posibles campos de análisis vinculados con la inseguridad en el transporte público: uno incumbe a las situaciones de inseguridad en sí (de acoso, robos y peleas), y otro a la gestión del servicio de transporte público. La gestión del servicio de transporte es normalmente desconsiderada como componente de la inseguridad urbana, pero se observa que repercute sobre las preocupaciones y percepciones de los usuarios/as y sobre sus prácticas de movilidad. La percepción de inseguridad de los usuarios se expresa en estrategias que interactúan con la gestión del servicio. Y, asimismo, tienen efecto sobre su uso.

Se alcanzan a reconocer incluso preocupaciones susceptibles de ser asociadas con momentos diferenciados del viaje en transporte público: unas relativas al momento previo al abordaje, vinculadas con la incertidumbre de información sobre el servicio; y otras relativas al momento a bordo del vehículo, vinculadas con la integridad física y las condiciones de prestación del servicio. Abordar el problema de la inseguridad en el transporte público contribuye en cierto modo a incorporar la dimensión espacial de la violencia/miedo al identificar situaciones con contextos concretos; y contribuye también a comprender la multifactorialidad de los procesos que construyen la inseguridad ciudadana, y que involucran aspectos de la calidad del entorno urbano y de la prestación del servicio de transporte público.

El registro y clasificación del tipo de situaciones de inseguridad en el transporte público da a conocer que el problema afecta a los usuarios en general, pero a las mujeres en especial; y aporta a la emergencia de comportamientos violentos, naturalizados y cotidianos, como el acoso.

La movilidad de varones y mujeres en el AMBA revela un patrón de género, observable por medio de los transportes utilizados (públicos y privados) y los motivos de viaje (en particular los de cuidado). La lectura de los datos primarios recogidos por este trabajo revela que la inseguridad en el transporte público también lo tiene. Las prácticas y estrategias de movilidad territorios 39

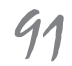


ponen en evidencia diferentes niveles del problema de la inseguridad entre varones y mujeres, así como diferentes apropiaciones.

Los resultados indican que el $72 \%$ de las mujeres usuarias se sintieron inseguras en el transporte público durante el último año, frente al $58 \%$ de los usuarios varones. Y que esta sensación es mayor entre aquellas mujeres que son madres de niñas/niños menores de 15 años, y entre aquellas que pertenecen a los hogares de menor nivel socioeconómico. Esta evidencia, aunque inicial, brinda pistas para indagar a futuro y con mayor profundidad no solo sobre la condición de género en la percepción y experiencia de la inseguridad sino sobre su interacción con la condición socioeconómica, la edad, el ciclo de vida del hogar y las capacidades y habilidades diferenciales de las mujeres.

Los resultados también indican que los robos y peleas son situaciones vistas y experimentadas por igual entre usuarios varones y mujeres, en tanto las situaciones de acoso son experimentadas mayormente por mujeres, a bordo del transporte público y bajo una diversidad de circunstancias, indistintas. Esto deja entrever que el transporte público expresa y contiene relaciones sociales que refuerzan y reproducen desigualdades de género (entre otras), y no es solo un medio técnico ni neutral. Y que es relevante incluir en el análisis de la inseguridad urbana la particular interacción que se produce en el transporte público, tanto de las identidades sociales como de los cuerpos físicos, y que de manera combinada conjugan una diferencia notable y desfavorable para las mujeres.
La movilidad de las mujeres presenta estrategias rutinarias de securización con implicancias (personales y familiares) invisibilizadas y a la vez diversas. Lo concreto es que la inseguridad en el transporte público funciona como condicionante de género. Las mujeres experimentan (y no solo perciben) un obstáculo extra a la hora de hacer efectiva su movilidad cotidiana, $y$ tienden a modificar o ajustar sus decisiones y patrones de viaje cuando entra en juego la inseguridad. Esto refuerza la significación de la ocurrencia de robos, peleas y acoso en el transporte público en términos de las consecuencias tanto físicas como de acceso a derechos.

Recuperar las percepciones y experiencias de los usuarios permite visibilizar la forma en que la (in)seguridad está siendo construida en el transporte público. Asimismo, permite entrever el papel del transporte público (y en particular, el de la gestión operativa del servicio) como parte de la inseguridad urbana y no solo como receptor de un problema ajeno y que lo excede. Esto es pertinente para involucrar y empoderar la agenda sectorial y también para llamar la atención sobre la agenda de políticas vinculadas con el derecho a la ciudad, las equidades de acceso y de género, y sobre la gestión del servicio y las prácticas personales.

\section{Referencias}

Allen, H., Pereyra, L., Sagaris, L., \& Cárdenas, G. (2017). Ella se mueve segura. She moves safely. A study on women's 
personal security and public transport in three latin american cities. FIA Foundation Research Series, Paper 10. Recuperado de https://www.fiafoundation. org/media/461162/ella-se-mueve-segura-she-moves-safely.pdf

Argentina, Ministerio de Transporte de la Nación (2012). Encuesta de Movilidad Domiciliaria para el Área Metropolitana de Buenos Aires (ENMODO) 20092010.

Argentina, Instituto Nacional de Estadísticas y Censos (INDEC). (2013). Encuesta sobre trabajo no remunerado y uso del tiempo.

Baele, S. J., \& Thomson, C. (2017). An Experimental Agenda for Securitization Theory. International Studies Review. Recuperado de https://academic.oup. $\mathrm{com} / \mathrm{isr} /$ article/3884515

Balzacq, T. (2010). Securitization theory: how security problems emerge and dissolve. Abingdon: Routledge.

Banco Mundial (2010). Mainstreaming gender in road transport: operational guidance for World Bank Staff. Transport Paper Series 28. Recuperado de https://openknowledge.worldbank. org/handle/10986/17455 License: CC BY 3.0 IGO

Bardelli, M. G., Szczyry, R., \& Verdaguer. F. (2016). El género como un factor determinante en la siniestralidad vial. Recuperado de http://www.congresodevialidad.org.ar/TRA/TRA-031.pdf Bergman, M., \& Kessler, G. (2009). Vulnerabilidad al delito y sentimiento de inseguridad en Buenos Aires. Desarrollo Económico, 48(190-191), 209-234. Bottazzi, M. F., Gallo. G., Lesgart, P., Mattía, C., \& Rojas. S. (2011). La seguridad vial desde un enfoque de género. Debates y desafios. Recuperado de http:// contralaviolenciavial.org/uploads/file/ DOCUMENTOS/la\%20seguridad\%20 vial $\% 20$ desde $\% 20$ un $\% 20$ enfoque $\% 20$ de $\% 20$ genero_\%20debates $\% 20 y \% 20$ desafios.pdf

Breengaard, M., Christensen, H., Oldrup, H., Poulsen, H., \& Malthesen, T. (2007). TRANSGEN - Gender mainstreaming european transport research and policies: Building the knowledge base and mapping good practices. Copenhague: University of Copenhagen.

Cedillo, H. P. (2011). Los avatares del cuerpo en la constitución de la identidad: un acercamiento a través de la obra de Pierre Bourdieu y Marcel Mauss. Géneros. Revista de investigación y divulgación sobre los estudios de género, 9(2), 18.

Colectivo Ni Una Menos (2016). $1^{o}$ índice nacional de violencia machista. Reporte nacional. Recuperado de http://contalaviolenciamachista.com/

Colella, V. (2013). Transformaciones, persistencias y resistencias del territorio: la ribera del Municipio de Vicente López. V Seminario Internacional de Investigación en Urbanismo. DUOT, Barcelona.

Delbosc A., \& Currie, G. (2012). Modelling the causes and impacts of personal safety perceptions on public transport ridership. Transport Policy, 24, 302-309. tersitarias 39

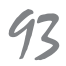


Díaz, M. M., \& Jiménez, F. (2007). Transportes y movilidad: ¿necesidades diferenciales según género? Terr@Plural, Ponta Grossa, 1, 91-101.

Di Virgilio, M., \& Vio, M. (2009). La geografía del proceso de formación de la Región Metropolitana de Buenos Aires. Recuperado de http://www.lahn. utexas.org/ Case\%20Study\%20Cities/Innerburb/ BA/UrbanizacionAMBA.pdf

Falú, A. (2009). Violencias y discriminaciones en las ciudades. En: A. Falú (ed.) Mujeres en la ciudad. De violencias y derechos. Red Mujer y Hábitat de América Latina. (pp. 15-37). Santiago de Chile: Ediciones SUR.

Fernández, L. P. (2015). Estudiar y trabajar desde el conurbano norte. Dossier Prácticas de oficio 16. Recuperado de ides.org.ar/wp.../Fernandez-LopesEstudiar-y-trabajar-en-el-ConurbanoNorte.pdf

Gutiérrez, A. (2011). Insumos para una gestión intersectorial de políticas públicas: movilidad y acceso. Territorios, 25, 151-172. Recuperado de https:// revistas.urosario.edu.co/index.php/ territorios/article/view/1850

Gutiérrez, A. (2012). ¿¿Qué es la movilidad? Revista Bitácora, 21(2), 61-74. Recuperado de http://www.revistas.unal. edu.co/index.php/bitacora

Gutiérrez, A. (2015). Movilidad cotidiana y metrópolis: desafíos de una dinámica contradictoria. En M. Arroyo, \& R. Cruz (coord.) Território e Circulação. A

\section{territarios 39}

94 dinâmica contraditória da globalização (pp. 313-342). São Paulo: AnnaBlume.
Gutiérrez, A. (2016). Direito a la mobilidade. Direitos e mobilidade. En L. Pires \& L. Andrada (orgs.), Mobilidade urbana. Desafíos e sustentabilidade (pp. 41-59). São Paulo: Ponto e Linha. Recuperado de http://cidadeemmovimento.org/ mobilidade-urbana-desafios-e-sustentabilidade-com-participacao-do-ivme-lancado/

Gutiérrez, A., \& Reyes. M. (2017). Mujeres entre la libertad y la obligación. Prácticas de movilidad cotidiana en el Gran Buenos Aires. Revista Transporte y Territorio, 16, 147-166. Recuperado de http://revistascientificas. filo.uba.ar/index.php/rtt/article/ view/3607/3302

Habitat International Coalition - América Latina. (2008). El Derecho a la Ciudad en el mundo: compilación de documentos relevantes para el debate. Recuperado de http://www.hic-al.org/publicaciones. cfm?pag=publicderviv

Hábitat III. (2015a). Temas Hábitat III. 3. Ciudades más seguras. Recuperado de http://habitat3.org/wp-content/ uploads/Issue-Paper-3_Safer-CitiesSP.pdf

Hábitat III. (2015b). Temas Hábitat III. 19. Transporte y movilidad. Recuperado de http://habitat3.org/wpcontent/uploads/Issue-Paper-19_ Transporte_y_movilidad-SP.pdf

Hanson, S. (2010). Gender and mobility: new approaches for informing sustainability. Gender, Place \& Culture: A Journal of Feminist Geography, 17(1), 5-23. 
Jirón, P. (2007). Implicancias de género en las experiencias de movilidad cotidiana urbana en Santiago de Chile. Revista venezolana de estudios de la mujer, 12(29).

Jirón, P., \& Zunino, S. D (2017). Dossier Movilidad urbana y género: experiencias latinoamericanas. Revista Transporte y Territorio, 16, 1-8.

Kessler. G. (2012). Delito, sentimiento de inseguridad y políticas públicas en la Argentina del siglo XxI. Recuperado de http://www.biblioteca.clacso.edu. ar/clacso/gt/201211230431 23/Lainseguridadylaseguridadciudadana.pdf

Kunieda, M., \& Gauthier, A. (2007). Género y transporte urbano: inteligente y asequible. Eschborn: Deutsche Gesellschaft für Technische Zusammenarbeit (GTZ).

Law, R. (1999). Beyond 'women and transport': towards new geographies of gender and daily mobility. Progress in $\mathrm{Hu}$ man Geography, 23(4), 567-588.

Lindón, A. (2008). Violencia/miedo: espacialidades y ciudad. Casa del tiempo, 4, 8-14.

Lindón, A. (2011). Revisitar la concepción de lo social para una Geografía constructivista. En: P. Zusman, R. Haesbaert, H. Castro \& S. Adamo (eds.) Geografias culturales. Aproximaciones, intersecciones y desafíos (pp. 177-212). Buenos Aires: UBA.

Massey, D. (1994). Space, Place and Gender. Minneapolis: University of Minnesota Press.
Quiros, T., Mehndiratta, S., \& Ochoa, C. (2014). Gender, travel and job access: evidence from Buenos Aires. Banco Mundial, Washington D.C. Recuperado de http://siteresources.worldbank.org/INTURBANTRANSPORT/ Resources/2014-Feb-5-Gender-andMobility.pdf

Scott, J. (1993). La Mujer trabajadora en el siglo XIX. En: Duby, G. y M. Perrot (eds.), Historia de las mujeres en Occidente (pp. 405-436). Madrid: Taurus.

Segura, R. (2006). Segregación residencial, fronteras urbanas y movilidad territorial. Un acercamiento etnográfico. Cuadernos del IDES, 9, 25.

Soto, V. P. (2007). Ciudad, ciudadanía y género. Problemas y paradojas. Territorios, 16-17, 29-45.

Universidad Nacional de Tres de Febrero (UNTREF), CINEA (2016). Ni una menos. Estudio de opinión pública para el AMBA. Rrecuperado de http://untref.edu.ar/ wpcontent/uploads/2016/06/Estudio_Ni_Una_Menos.pdf

Zunino, S. D. (2014). Experiencias pasajeras: prácticas y representaciones de la movilidad cotidiana en el Buenos Aires de principios de siglo $\mathrm{XX}$. X Jornadas de Investigadores en Historia, Buenos Aires, Argentina.

Wilhelmsen, J. (2017). How does war become a legitimate undertaking? Re-engaging the post-structuralist foundation of securitization theory. Cooperation and Conflict, 52(2), 166-183. 
